\title{
Smary do systemów przekładni - aktualne klasyfikacje i wymagania jakościowe
}

\section{Lubricating greases for gear systems - current classifications and quality requirements}

\author{
Agnieszka Skibińska \\ Instytut Nafty i Gazu - Państwowy Instytut Badawczy
}

\begin{abstract}
STRESZCZENIE: W przypadku smarów plastycznych istnieje niewiele specyfikacji normatywnych określających wymagania w stosunku do nich, poza smarami do specjalistycznych zastosowań wojskowych. W artykule przedstawiono międzynarodową klasyfikację środków smarowych zgodnie z PN-ISO 6743-99 Środki smarowe, oleje przemysłowe i produkty podobne (klasa L) - Klasyfikacja - Część 99: Postanowienia ogólne. Zaprezentowano również klasyfikację smarów zgodnie z PN-ISO 6743-9 Środki smarowe, oleje przemysłowe i produkty podobne (klasa L) - Klasyfikacja - Część 9: Grupa X (Smary plastyczne), a także oznaczenie smarów zgodnie z PN-ISO 12924 Środki smarowe, oleje przemysłowe i produkty podobne (Klasa L) - Grupa X (Smary) - Wymagania. Dla środków smarowych stosowanych w systemach przekładni przedstawiono klasyfikację zgodną z PN-ISO 6743-6 Środki smarowe, oleje przemystowe i produkty podobne (klasa L) - Klasyfikacja - Czesść 6: Grupa C (Przektadnie). Zebrano wymagania dla smarów plastycznych do przekładni zgodnie z aktualnymi wersjami norm: PN-C-96015 Środki smarowe - Smary plastyczne klasy G-Klasyfikacja i wymagania, DIN 51826 Lubricants - Lubricating greases G-Classification and requirements, a także projektem ISO/CD 12925-3 Lubricants, Industrial oils and related products (Class L) - Family C (gears). Part 3 - Specifications for greases for enclosed and open gear systems.
\end{abstract}

Słowa kluczowe: smary plastyczne, smary do systemów przekładni, klasyfikacja, wymagania.

\begin{abstract}
There are few normative specifications defining the requirements for lubricating greases, apart from greases for specialized military applications. The article presents the international classification of lubricants according to ISO 6743-99 Lubricants, industrial oils and related products (class L) - Classification - Part 99: General. The classification of greases is presented according to ISO 6743-9 Lubricants, industrial oils and related products (class L) - Classification - Part 9: Family X (Greases) and marking of greases according to ISO 12924 Lubricants, industrial oils and related products (Class L) - Family X (Greases) - Specification. For lubricants used in gear systems, the classification according to ISO 6743-6 Lubricants, industrial oils and related products (class L) - Classification - Part 6: Family C (Gears) was presented. Requirements for lubricating greases for gears have been collected in accordance with the current versions of PN-C-96015 Lubricants - Lubricating greases $G$-Classification and requirement, DIN 51826 Lubricants - Lubricating greases G-Classification and requirements and the project ISO/CD 12925-3 Lubricants, Industrial oils and related products (Class L) - Family C (gears). Part 3 - Specifications for greases for enclosed and open gear systems.
\end{abstract}

Key words: lubricating greases, greases for gear systems, classification, requirements.

\section{Klasyfikacja środków smarowych}

Klasyfikacja przemysłowych środków smarowych opracowana została przez Międzynarodową Organizację Normalizacyjną (ISO) w połączeniu z normami wymagań jakościowych opracowanymi również przez ISO. Aktualna norma klasyfikacyjna PN-ISO 6743-99 wprowadza klasyfikację środków smarowych, dzieląc je na 18 grup ze względu na zastosowanie:
- A - Układy smarowania przelotowego;

- B - Antyadhezyjna ochrona form;

- C - Przekładnie;

- D - Sprężarki;

- E - Oleje do silników wewnętrznego spalania;

- F - Wrzeciona, łożyska i sprzęgła współpracujące;

- $\mathrm{G}$ - Prowadnice ślizgowe;

- H - Układy hydrauliczne;

- M-Obróbka metali;

Autor do korespondencji: A. Skibińska, e-mail: agnieszka.skibinska@inig.pl

Artykuł nadesłano do Redakcji: 11.01.2021 r. Zatwierdzono do druku: 26.05.2021 r. 
- $\quad \mathrm{N}$ - Izolacje elektryczne;

- P-Narzędzia pneumatyczne;

- Q-Ciekłe nośniki ciepła;

- $\mathrm{R}$ - Czasowa ochrona przed korozją;

- T-Turbiny;

- U - Obróbka cieplna;

- $\mathrm{X}$ - Smary plastyczne;

- Y - Inne zastosowania;

- Z-Cylindry maszyn parowych.

\section{Klasyfikacja środków smarowych stosowanych w systemach przekładni}

W normie PN-ISO 6743-6 podano szczegółową klasyfikację grupy C (przekładnie). Klasyfikacja ta dotyczy tylko środków smarowych do przekładni przemysłowych i wyróżnia:

a) środki smarowe do przekładni zamkniętych:

- stosowane przy smarowaniu ciągłym rozbryzgowym lub natryskowym:

- oleje kategorii CHB, CKC, CKD i CKE,

- środki smarowe kategorii CKS i CKT;

- stosowane przy smarowaniu ciągłym rozbryzgowym: - smary kategorii CKG;

b) środki smarowe do przekładni otwartych i półzamkniętych:

- stosowane przy smarowaniu okresowym przez zanurzenie lub mechaniczne nanoszenie:

- produkty kategorii CKH i CKJ,

- smary kategorii CKL;

- okresowo stosowane:

- produkty kategorii CKM.

\section{Klasyfikacja i oznaczenie smarów}

Klasyfikację smarów przedstawia norma PN-ISO 6743-9, przyjmując za podstawę warunki ich eksploatacji, gdyż z uwagi na zróżnicowane właściwości smarów nie ma możliwości sklasyfikowania ich według typu smarowanych elementów.

Zgodnie z PN-ISO 8681 pełne oznaczenie smaru, czyli: ISO - L - X - symbol 1 - symbol 2 - symbol 3 - symbol 4 kod konsystencji NLGI, zawiera:

- skrót ISO;

- literę L, która określa klasę ,środka smarowego, oleju przemysłowego i produktu podobnego";

- rodzaj smaru - oznaczenie złożone z grupy 5 liter, z których każda w tej kolejności, w jakiej jest napisana, ma odpowiednie znaczenie:

- litera X dla oznaczenia grupy smaru;

- najniższa temperatura stosowania smaru (symbol 1);
- najwyższa temperatura stosowania smaru (symbol 2);

- zdolność smaru do zapewnienia właściwego smarowania w obecności wody i do zapewnienia odpowiedniej ochrony przed rdzewieniem (symbol 3);

- zdolność smaru do zapewnienia właściwego smarowania w warunkach dużych nacisków (symbol 4);

- klasa konsystencji smaru według NLGI.

Szczegółowe wymagania dla smarów, określające każdy z powyższych symboli (od 1 do 4 ), zamieszczono w normie PN-ISO 12924.

Symbol 1 - najniższą temperaturę stosowania (1A do 1E) określa się według kryterium płynności w danej temperaturze z zastosowaniem oznaczeń:

- $\quad$ penetracji w temperaturze minusowej według ISO 13737;

- lub ciśnienia przepływu według DIN 51805;

- lub momentu rozruchowego i momentu roboczego według ASTM D 1478.

Symbol 2 - najwyższą temperaturę stosowania określa się według:

- temperatury kroplenia dla 2 A i 2 B według ISO 2176, ISO 6299, IP 396 lub NF T60-627;

- kryterium testu dynamicznego w łożysku, w określonej temperaturze, według DIN 51821-2 - dla 2 C do 2 G.

Symbol 3 stanowi połączenie dwóch właściwości:

- odporności na kontakt z wodą, z zastosowaniem:

- ISO 11009 dla warunków dynamicznego wymywania wodą (w przypadku smarów od A do D odporność na wymywanie wodą powinna być określona w temperaturze $38^{\circ} \mathrm{C}$, a w przypadku smarów z symbolem od E do $\mathrm{G}-\mathrm{w}$ temperaturze $79^{\circ} \mathrm{C}$ ),

- DIN 51807-1 dla warunków statycznych;

- oraz poziomu ochrony przed rdzewieniem, określanego z zastosowaniem ISO 11007.

Symbol 4 wyznacza się poprzez oznaczenie obciążenia zespawania w badaniu aparatem czterokulowym - z zastosowaniem metodyki IP 239 (dla warunków europejskich) lub ASTM D 2596 (dla warunków amerykańskich).

Klasę konsystencji według NLGI określa się poprzez pomiar penetracji po 60 cyklach ugniatania zgodnie z ISO 2137.

\section{Klasyfikacja i wymagania stawiane smarom stosowanym w przekładniach}

Klasyfikację, jak również wymagania dotyczące smarów plastycznych do przekładni można znaleźć w dwóch normach: PNC-96015 oraz DIN 51826, a także w projekcie ISO/CD 12925-3, który w najbliższym czasie powinien uzyskać status normy.

Zgodnie z PN-C-96015 smary plastyczne klasy G w klasach konsystencji od 2 do 000 składają się z olejów mineral- 
nych i/lub olejów syntetycznych oraz zagęszczacza, dopuszczalne są dodatki substancji uszlachetniających i/lub stałych dodatków smarnościowych.

Pełne oznaczenie smaru klasy G zawiera: smar plastyczny DIN 51826 - rodzaj smaru - klasę konsystencji - oznaczenie literowe - dodatkową liczbę.

Wyróżniane są trzy rodzaje smarów plastycznych G:

- smary plastyczne klasy GP - z substancjami czynnymi dla zmniejszenia zużycia i zwiększenia wytrzymałości w obszarze tarcia mieszanego;

- $\quad$ smary plastyczne klasy GF - zawierające stałe dodatki smarnościowe;

- smary plastyczne klasy G na bazie olejów syntetycznych. Oznaczenie literowe (C, D, E, F, G, H, K) jest połączeniem dwóch właściwości:

- najwyższej temperatury stosowania (nie podano metody wyznaczenia);

- zachowania w obecności wody według DIN 51807-1.

Dodatkowa liczba $(10,20,30,40,50,60)$ określa najniższą temperaturę stosowania, nie podano metody wyznaczenia tego parametru, można zastosować IP 186.
Wymagania dla smarów plastycznych G przedstawiono w tabelach 1-3.

Wymagania dla środków smarowych stosowanych w przekładniach przedstawione są w następujących dokumentach:

- w normie ISO 12925-1 - dla olejów do zamkniętych przekładni zębatych, kategorii: CKB, CKC, CKD, CKSMP, CKE, CKTG, CKES, CKPG, CKPR, CSPG, CSPR, CTPG, CTPR;

- w dokumencie ISO/CD 12925-2 - dla produktów smarowych o wysokiej lepkości, klas: CKH, CKJ, CKJ-F, CKJTG, CKJES, CKJPG, CKJPR i CKM, do otwartych i częściowo zamkniętych układów przekładni;

- w dokumencie ISO/CD 12925-3 - dla smarów kategorii CKG i CKL, do zamkniętych i otwartych systemów przekładni. Zgodnie z ISO/CD 12925-3 wyróżniono dwie kategorie smarów:

- smary do systemów zamkniętych przekładni, kategorii CKG, stosowane do smarowania rozbryzgowego; wyróżniono tu podkategorie: CKGB, CKGD, CKGPG, CKGPR oraz przyjazne dla środowiska podkategorie: CGTG, CGEC, CGPG, CGPR:

Tabela 1. Wymagania dla smarów plastycznych G według PN-C-96015

Table 1. Requirements for lubricating greases according to PN-C-96015

\begin{tabular}{|c|c|c|c|c|c|c|c|c|}
\hline Wlaściwość & $\mathbf{C}$ & D & $\mathbf{E}$ & $\mathbf{F}$ & G & $\mathbf{H}$ & $\mathbf{K}$ & $\begin{array}{l}\text { Badanie } \\
\text { wedlug: }\end{array}$ \\
\hline Zachowanie w obecności wody & $\begin{array}{l}0-40 \\
1-40\end{array}$ & $\begin{array}{l}2-40 \\
3-40\end{array}$ & $\begin{array}{l}0-40 \\
1-40\end{array}$ & $\begin{array}{l}2-40 \\
3-40\end{array}$ & $\begin{array}{l}0-90 \\
1-90\end{array}$ & $\begin{array}{l}2-90 \\
3-90\end{array}$ & do uzgodnienia & DIN 51807-1 \\
\hline Najwyższa temperatura stosowania $\left[{ }^{\circ} \mathrm{C}\right]$ & \multicolumn{2}{|c|}{$\leq 60$} & \multicolumn{2}{|c|}{$\leq 80$} & \multicolumn{2}{|c|}{$\leq 100$} & $>100$ & a \\
\hline Temperatura kroplenia $\left[{ }^{\circ} \mathrm{C}\right]$ & \multicolumn{2}{|c|}{$>90$} & \multicolumn{2}{|c|}{$>110$} & \multicolumn{2}{|c|}{$>130$} & $\begin{array}{l}\text { podane przez } \\
\text { dostawcę }\end{array}$ & DIN ISO 2176 \\
\hline Najniższa temperatura stosowania $\left[{ }^{\circ} \mathrm{C}\right]$ & \multicolumn{7}{|c|}{ podane przez dostawcę } & $\mathrm{b}$ \\
\hline Ciśnienie przepływu ${ }^{\mathrm{c}}[\mathrm{hPa}]$ & \multicolumn{7}{|c|}{$\leq 200$} & DIN 51805 \\
\hline $\begin{array}{l}\text { Właściwości przeciwrdzewne według procedury SKF Emcor } \\
\text { [stopień korozji] }\end{array}$ & \multicolumn{6}{|c|}{$\leq 1$} & $\begin{array}{l}\text { podane przez } \\
\text { dostawcę }\end{array}$ & $\begin{array}{l}\text { ISO } 11007 \\
\text { i DIN } 51802\end{array}$ \\
\hline Działanie korodujące na miedzi [stopień korozji] & \multicolumn{2}{|c|}{$\leq 2 \mathrm{w} 60^{\circ} \mathrm{C}$} & \multicolumn{2}{|c|}{$\leq 2 \mathrm{w} 80^{\circ} \mathrm{C}$} & \multicolumn{2}{|c|}{$\leq 2 \mathrm{w} 100^{\circ} \mathrm{C}$} & $\begin{array}{l}\text { podane przez } \\
\text { dostawcę }\end{array}$ & DIN 51811 \\
\hline Zawartość zanieczyszczeń stałych ponad $25 \mu \mathrm{m}$ w mg/kg & \multicolumn{7}{|c|}{ podawana na życzenie przez dostawcę $\leq 20^{\mathrm{d}}$} & DIN 51813 \\
\hline Zagęszzczacz & \multicolumn{7}{|c|}{ rodzaj podawany przez dostawcę } & DIN 51820-1 \\
\hline Olej bazowy & \multicolumn{7}{|c|}{ rodzaj i lepkość $\left(40^{\circ} \mathrm{C}\right.$ i $\left.100^{\circ} \mathrm{C}\right)$ są podawane przez dostawcę } & $\begin{array}{l}\text { DIN } 51820-1 \\
\text { DIN } 51562-1\end{array}$ \\
\hline Badanie biodegradacji [\%] & \multicolumn{7}{|c|}{$\geq 80^{\mathrm{e}}$} & $\begin{array}{l}\text { DIN } 51828-1 \\
\text { DIN } 51828-2\end{array}$ \\
\hline Stałe dodatki smarnościowe & \multicolumn{7}{|c|}{ rodzaj i ilość dodatku są podawane przez dostawcę } & \\
\hline $\begin{array}{l}\text { Badanie w aparacie czterokulowym Shella VKA, obciążenie } \\
\text { zespawania }[\mathrm{N}]\end{array}$ & \multicolumn{7}{|c|}{$\geq 2000$} & DIN 51350-4 \\
\hline
\end{tabular}

a) Nie istnieje obecnie znormalizowana metoda badań, tak więc zastosowanie mają odpowiednie badania laboratoryjne i doświadczenia z praktyki.

b) Nie istnieje obecnie znormalizowana metoda badań dla określenia najniższej temperatury stosowania, może ewentualnie zostać przytoczone IP 186, jednakże bez określenia punktów odniesienia.

c) Wskazana jest temperatura $\mathrm{w}{ }^{\circ} \mathrm{C}$, w której ciśnienie przepływu zostało utrzymane.

d) Nie dotyczy smarów plastycznych klasy G ze stałymi dodatkami smarnościowymi.

e) Dotyczy tylko smarów plastycznych szybko biodegradowalnych.

f) Dotyczy tylko smarów plastycznych klasy GP z dodatkami dla przenoszenia obciążenia. 
Tabela 2. Wymagania dla smarów plastycznych G według DIN 51826

Table 2. Requirements for lubricating greases according to DIN 51826

\begin{tabular}{|c|c|c|c|c|c|}
\hline Wlaściwość & \multicolumn{4}{|c|}{ Wymagania } & Badanie według: \\
\hline Najwyższa temperatura stosowania $\left[{ }^{\circ} \mathrm{C}\right]$ & $\leq 60$ & $\leq 80$ & $\leq 1$ & $>100$ & $\mathrm{~b}$ \\
\hline Temperatura kroplenia $\left[{ }^{\circ} \mathrm{C}\right]$ & $>90$ & $>110$ & $>1$ & $>130$ & DIN ISO 2176 \\
\hline Najniższa temperatura stosowania $\left[{ }^{\circ} \mathrm{C}\right]$ & \multicolumn{4}{|c|}{ należy określić } & $\mathrm{c}$ \\
\hline Ciśnienie przepływu ${ }^{\mathrm{d}}[\mathrm{hPa}]$ & \multicolumn{4}{|c|}{$\leq 200$} & DIN 51805 \\
\hline Zachowanie w obecności wody & \multicolumn{4}{|c|}{ należy określić } & DIN $51807-1^{\mathrm{e}}$ \\
\hline $\begin{array}{l}\text { Właściwości przeciwrdzewne według procedury SKF Emcor } \\
\text { [stopień korozji] }\end{array}$ & \multicolumn{4}{|c|}{$\leq 1$} & $\begin{array}{l}\text { ISO } 11007 \\
\text { lub DIN } 51802\end{array}$ \\
\hline Działanie korodujące na miedzi [stopień korozji] & $\leq 2 \mathrm{w} 60^{\circ} \mathrm{C}$ & & & $\leq 2 \mathrm{w} 100^{\circ} \mathrm{C}$ & DIN 51811 \\
\hline Zawartość zanieczyszczeń stałych ponad $25 \mu \mathrm{m} \mathrm{w} \mathrm{mg/kg}$ & \multicolumn{4}{|c|}{$\leq 20^{\mathrm{f}}$} & DIN 51813 \\
\hline Zagęszczacz & \multicolumn{4}{|c|}{ musi być określony przez dostawcę } & - \\
\hline Stałe dodatki smarnościowe & \multicolumn{4}{|c|}{ muszą być określone przez dostawcę } & - \\
\hline Olej bazowy & \multicolumn{4}{|c|}{$\begin{array}{l}\text { należy określić olej bazowy } \\
\text { należy określić lepkości }\left(40^{\circ} \mathrm{C} \text { i } 100^{\circ} \mathrm{C}\right)\end{array}$} & DIN 51562-1 \\
\hline
\end{tabular}

a) Smary G muszą być jednorodne i możliwie wolne od wtrąceń powietrza.

b) Nie istnieje obecnie znormalizowana metoda badań, tak więc zastosowanie mają odpowiednie badania laboratoryjne i doświadczenia z praktyki.

c) Obecnie nie ma znormalizowanej metody testowej do określania niższej temperatury roboczej; w razie potrzeby można zastosować IP 186 , ale bez ustawiania wartości odniesienia.

d) Wskazana jest temperatura $\mathrm{w}{ }^{\circ} \mathrm{C}$, w której ciśnienie przepływu zostało utrzymane.

e) Metoda badania zgodnie z DIN 51807-1 może być stosowana tylko do smarów G o klasie konsystencji od 0 do 2. Dla klas spójności 00 i 000 dopuszczalna jest analogia do bardziej trwałych konsystencji.

f) Nie dotyczy składników formulacji.

Tabela 3. Wymagania dla smarów plastycznych GP ${ }^{\mathrm{a}}$ według DIN 51826

Table 3. Requirements for lubricating greases according to DIN 51826

\begin{tabular}{|c|c|c|c|c|c|}
\hline Wlaściwość & \multicolumn{4}{|c|}{ Wymagania } & Badanie według: \\
\hline Najwyższa temperatura stosowania $\left[{ }^{\circ} \mathrm{C}\right]$ & $\leq 60$ & $\leq 80$ & \multicolumn{2}{|r|}{$>100$} & $\mathrm{~b}$ \\
\hline Temperatura kroplenia $\left[{ }^{\circ} \mathrm{C}\right]$ & $>90$ & $>110$ & \multicolumn{2}{|c|}{$>130$} & DIN ISO 2176 \\
\hline Najniższa temperatura stosowania $\left[{ }^{\circ} \mathrm{C}\right]$ & \multicolumn{4}{|c|}{ należy określić } & $\mathrm{c}$ \\
\hline Ciśnienie przepływu ${ }^{\mathrm{d}}[\mathrm{hPa}]$ & \multicolumn{4}{|c|}{$\leq 200$} & DIN 51805 \\
\hline Zachowanie w obecności wody & \multicolumn{4}{|c|}{ należy określić } & DIN $51807-1^{\mathrm{e}}$ \\
\hline $\begin{array}{l}\text { Właściwości przeciwrdzewne według procedury SKF Emcor } \\
\text { [stopień korozji] }\end{array}$ & \multicolumn{4}{|c|}{$\leq 1$} & $\begin{array}{l}\text { ISO } 11007 \\
\text { lub DIN } 51802\end{array}$ \\
\hline Działanie korodujące na miedzi [stopień korozji] & $\leq 2 \mathrm{w} 60^{\circ} \mathrm{C}$ & $\leq 2 \mathrm{w}$ & ${ }^{\circ} \mathrm{C}$ & $\leq 2 \mathrm{w} 100^{\circ} \mathrm{C}$ & DIN 51811 \\
\hline Zawartość zanieczyszczeń stałych ponad $25 \mu \mathrm{m} \mathrm{w} \mathrm{mg/kg}$ & \multicolumn{4}{|c|}{$\leq 20^{\mathrm{f}}$} & DIN 51813 \\
\hline Zagęszczacz & \multicolumn{4}{|c|}{ musi być określony przez dostawcę } & - \\
\hline Stałe dodatki smarnościowe & \multicolumn{4}{|c|}{ muszą być określone przez dostawcę } & - \\
\hline Olej bazowy & \multicolumn{4}{|c|}{$\begin{array}{l}\text { należy określić olej bazowy } \\
\text { należy określić lepkości }\left(40^{\circ} \mathrm{C} \mathrm{i} 100^{\circ} \mathrm{C}\right)\end{array}$} & DIN 51562-1 \\
\hline Badanie w aparacie czterokulowym VKA, obciążenie zespawania [N] & \multicolumn{4}{|c|}{$\geq 2000$} & DIN 51350-4 \\
\hline Badanie na maszynie wytrzymałościowej FZG, metoda badania A/2.8/50 & \multicolumn{4}{|c|}{$\mathrm{SKS} \geq 12$} & DIN ISO $14635-3^{\mathrm{g}}$ \\
\hline
\end{tabular}

a) Smary GP muszą być jednorodne i możliwie wolne od wtrąceń powietrza.

b) Nie istnieje obecnie znormalizowana metoda badań, tak więc zastosowanie mają odpowiednie badania laboratoryjne i doświadczenia z praktyki.

c) Obecnie nie ma znormalizowanej metody testowej do określania niższej temperatury roboczej; w razie potrzeby można zastosować IP 186, ale bez ustawiania wartości odniesienia.

d) Wskazana jest temperatura $\mathrm{w}{ }^{\circ} \mathrm{C}$, w której ciśnienie przepływu zostało utrzymane.

e) Metoda badania zgodnie z DIN 51807-1 może być stosowana tylko do smarów G o klasie konsystencji od 0 do 2 . Dla klas spójności 00 i 000 dopusz-

czalna jest analogia do bardziej trwałych konsystencji.

f) Nie dotyczy składników formulacji.

g) Dotyczy tylko klas NLGI 000-0. 
- to smary o konsystencji NLGI 000, 00, 0,

- wytworzone na bazie mineralnych i syntetycznych baz olejowych (w klasach lepkości ISO VG od 150 do 460) i różnego typu zagęszczaczy (najczęściej litowych i litowo-wapniowych),

- zawierające w swym składzie antyutleniacze i inhibitory korozji, mogą również zawierać dodatki poprawiające własności przeciwzatarciowe;

- smary do otwartych i częściowo zamkniętych przekładni, kategorii CKL, stosowane również do nakładania na zęby z przekładni otwartych; wyróżniono tu podkategorie: CKLC, CKLTG, CKLES, CKLPG, CKLPR:
- smary o konsystencji NLGI 0, 1, rzadziej 2,

- wytworzone na bazie mineralnych i syntetycznych baz olejowych (w klasach lepkości ISO VG od 680 do 3200) i różnego typu zagęszczaczy (najczęściej litowych i litowo-wapniowych),

- zawierające w swym składzie antyutleniacze i inhibitory korozji, mogą również zawierać dodatki poprawiające własności przeciwzatarciowe i stałe środki smarowe, takie jak grafit, dwusiarczki molibdenu itd.

Skład i właściwości dla wyżej wymienionych kategorii smarów (według załącznika A) przedstawiono w tabeli 4, wymagania w tabeli 5, a w tabeli 6 - wymagania środowiskowe.

Tabela 4. Skład i właściwości smarów do przekładni według ISO/CD 12925-3

Table 4. Composition and properties for gear greases according to ISO/CD 12925-3

\begin{tabular}{|c|c|c|c|c|c|c|c|c|}
\hline \multirow{2}{*}{$\begin{array}{l}\text { Kategoria } \\
\text { smaru }\end{array}$} & \multirow{2}{*}{$\begin{array}{c}\text { Olej bazowy } \\
\text { (charakter chemiczny) }\end{array}$} & \multicolumn{7}{|c|}{ Wlaściwości smarów } \\
\hline & & AO & IC & $\mathbf{S}$ & EP & AW & WR & $\mathbf{T}$ \\
\hline CKGB & mineralny & + & + & & & & & \\
\hline CKGD & mineralny & + & + & + & & & & \\
\hline CKGPG & poliglikole & + & + & & + & + & & \\
\hline CKGPR & polialfaolefiny & + & + & & + & + & & \\
\hline CGTG & trójglicerydy i ich pochodne & + & + & & + & + & & \\
\hline CGEC & estry syntetyczne & + & + & & + & + & & \\
\hline CGPG & poliglikole & + & + & & + & + & & \\
\hline CGPR & $\begin{array}{l}\text { mieszanka węglowodorów, polialfaolefin lub białych olejów mineral- } \\
\text { nych, będących głównym składnikiem, wraz z innymi typami olejów } \\
\text { bazowych (poliglikolami mieszalnymi z węglowodorami, estrami) }\end{array}$ & + & + & & + & + & & \\
\hline CKLC & mineralny & & + & & + & & + & + \\
\hline CKLTG & trójglicerydy i ich pochodne & & + & & + & & + & + \\
\hline CKLES & estry syntetyczne & & + & & + & & + & + \\
\hline CKLPG & poliglikole & & + & & + & & + & + \\
\hline CKLPR & $\begin{array}{l}\text { mieszanki węglowodorów, polialfaolefin lub białych olejów mineral- } \\
\text { nych, będących głównym składnikiem, wraz z innymi typami olejów } \\
\text { bazowych (poliglikolami mieszalnymi z węglowodorami, estrami) }\end{array}$ & & + & & + & & + & + \\
\hline
\end{tabular}

AO - antyutleniające, IC - ochrony przed korozją metali żelaznych i nieżelaznych, S - przeciwzatarciowe, EP - przenoszenia ekstremalnych nacisków, AW - przeciwzużyciowe, WR - odporność na wymywanie wodą, T - adhezja

Tabela 5. Wymagania dla smarów do przekładni według ISO/CD 12925-3

Table 5. Requirements for gear greases according to ISO/CD 12925-3

\begin{tabular}{|c|c|c|c|c|c|c|}
\hline \multirow{2}{*}{ Wlaściwości } & \multirow{2}{*}{$\begin{array}{c}\text { Metody } \\
\text { badawcze }\end{array}$} & \multirow{2}{*}{ Jednostka } & \multicolumn{4}{|c|}{ Klasa konsystencji NLGI } \\
\hline & & & 000 & 00 & $\mathbf{0}$ & 1 \\
\hline Penetracja w $25^{\circ} \mathrm{C}$ [min-max] & ISO 2137 & $1 / 10 \mathrm{~mm}$ & $445-475$ & $400-430$ & $365-385$ & $310-340$ \\
\hline $\begin{array}{l}\text { Odporność na ścinanie, po ugniata- } \\
\text { niu po } 100000 \text { cyklach }\end{array}$ & ISO 2137 & $1 / 10 \mathrm{~mm}$ & \multicolumn{2}{|c|}{ nie wymagane } & \multicolumn{2}{|c|}{$\begin{array}{l}\text { nie powinno być większej różnicy niż } 75 \\
{[\mathrm{~mm} / 10] \text { od penetracji po ugniataniu }(60 \mathrm{x})}\end{array}$} \\
\hline Temperatura kroplenia & $\begin{array}{c}\text { ISO } 2176 \\
\text { lub ISO } 6299 \\
\text { lub ISO } 22286\end{array}$ & ${ }^{\circ} \mathrm{C}$ & \multicolumn{4}{|c|}{ podawać } \\
\hline Wydzielanie oleju w $40^{\circ} \mathrm{C}$ & ISO 22285 & $\%(m / m)$ & \multicolumn{4}{|c|}{ podawać } \\
\hline Ochrona przed korozją $\left(100^{\circ} \mathrm{C} / 24 \mathrm{~h}\right)$ & ISO 2160 & ocena & \multicolumn{4}{|c|}{$<2$} \\
\hline Ochrona przed rdzą ${ }^{\mathrm{a}}[\max ]$ & ISO 11007 & ocena & \multicolumn{2}{|c|}{ do uzgodnienia } & \multicolumn{2}{|c|}{$2-2$} \\
\hline
\end{tabular}


cd. Tabela 5/ cont. Table 5

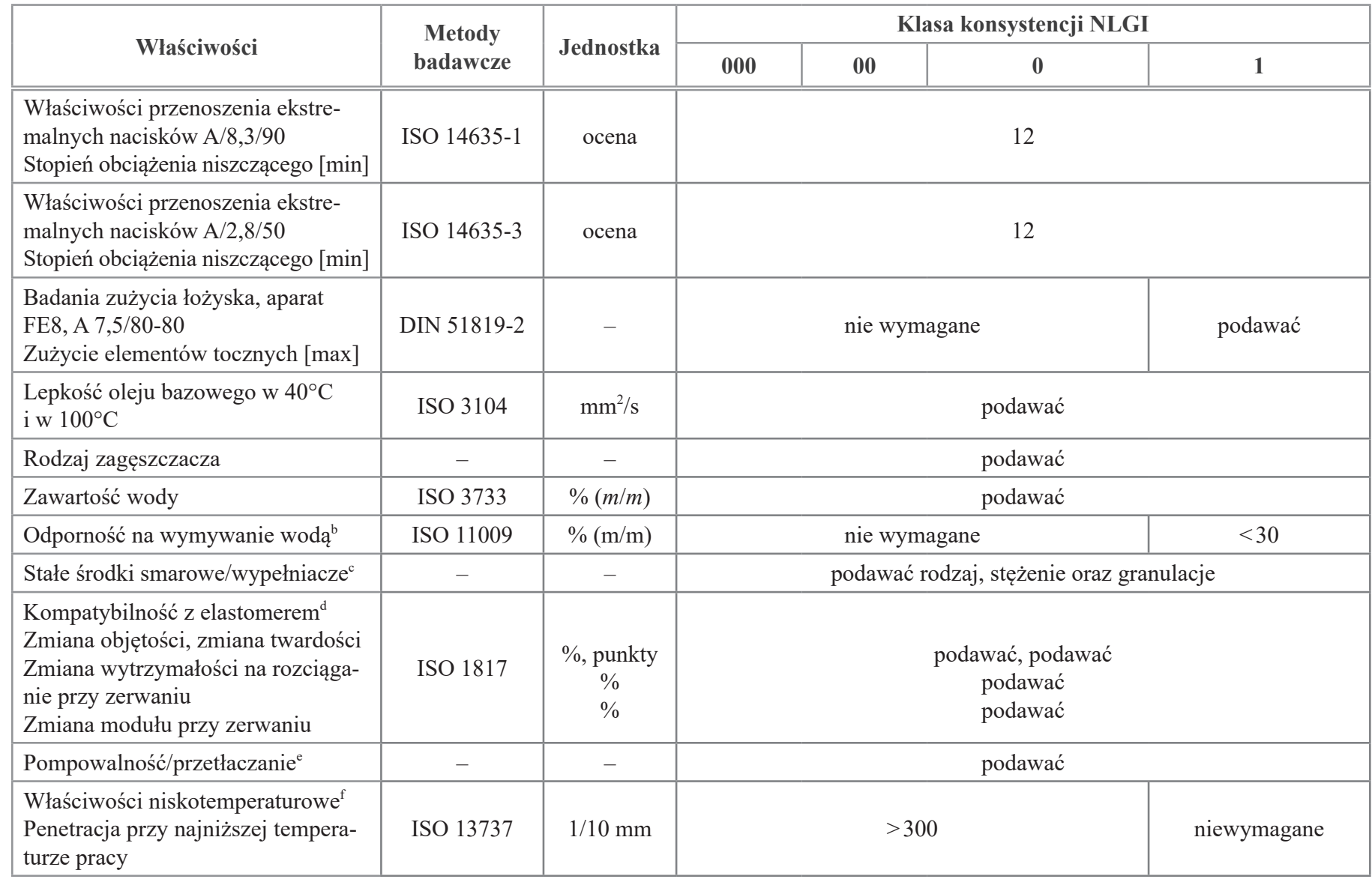

a) Właściwości ochrony przed korozją: w trudnych warunkach atmosferycznych, dodatkowe właściwości przeciwrdzewne mogą być wymagane dla produktów klasy CKL (dla otwartych i półzamkniętych przekładni). Norma ISO 11007 nie znajduje zastosowania do smarów o klasie NLGI 000 i 00. W każdym przypadku metody badawcze i limity powinny być negocjowane pomiędzy odbiorcą i dostawcą.

b) ISO 11009 nie ma zastosowania do smarów bardziej miękkich niż klasy NLGI N 1 . Dla produktów klasy CKL metody badawcze i limity powinny być negocjowane pomiędzy odbiorcą i dostawcą.

c) Stałe środki smarowe/wypełniacze: dotyczy produktów typu - F.

d) Elastomer, temperatura i czas trwania, limity dla różnych właściwości elastomerów powinny być negocjowane pomiędzy odbiorcą i dostawcą.

e) Dotyczy produktów klasy CKL. Metody badawcze i limity powinny być negocjowane pomiędzy odbiorcą i dostawcą.

f) Lub każda inna pasująca metoda. Dotyczy klasy CKG. Dostawca powinien wykazać, że w temp. początkowej smar nie zastyga oraz posiada dobre smarowanie dla stykających się części przekładni.

Tabela 6. Wymagania środowiskowe dla smarów do przekładni według ISO/CD 12925-3

Table 6. Environmental requirements for gear greases according to ISO/CD 12925-3

\begin{tabular}{|c|c|c|c|}
\hline Badana właściwość & Jednostka & Wymaganie & Metoda badania \\
\hline Biodegradowalność, minimum ${ }^{\mathrm{a}, \mathrm{c}}$ & $\%$ & 50 & $\begin{array}{c}\text { ISO } 14593 \\
\text { lub ISO } 9439 \text {, } \\
\text { lub ISO } 16221 \text {, } \\
\text { lub ISO } 9408\end{array}$ \\
\hline $\begin{array}{l}\text { Toksyczność } \\
\text { EC } 50 \text { (hamowanie wzrostu glonów lub hamowanie wzrostu glonów morskich) }\end{array}$ & $\mathrm{mg} / \mathrm{l}$ & $>100$ & $\begin{array}{c}\text { ISO } 8692 \\
\text { lub ISO } 10253\end{array}$ \\
\hline $\begin{array}{l}\text { Toksyczność w środowisku lądowym. Badanie na roślinie lądowej: badanie } \\
\text { kiełkowania siewek i wzrostu siewek }\end{array}$ & $\%$ & podawać & OECD 208 \\
\hline EC 50 (rozwielitki lub widłonogi) & $\mathrm{mg} / \mathrm{l}$ & $>100$ & $\begin{array}{c}\text { ISO } 6341 \\
\text { lub ISO } 14669\end{array}$ \\
\hline LC 50 (ryba) & $\mathrm{mg} / \mathrm{l}$ & $>100$ & ISO 7346-1 \\
\hline Zawartość węgla o biologicznym pochodzeniu, minimium ${ }^{\mathrm{b}}$ & $\%$ & 25 & ASTM D 6866 \\
\hline
\end{tabular}

a) Wszystkie rzeczywiste ekologiczne oznakowania, przepisy i zalecenia odnoszą się do metod badania ISO i EN podanych w niniejszej tablicy. Obecnie brak jest stosownych norm dotyczących potwierdzania biodegradowalności w innych środowiskach (np. składowisko odpadów), chociaż trwają prace rozwojowe. Informacje dotyczące precyzji są obecnie w fazie opracowywania.

b) Dotyczy tylko produktów typu CKLTG, CKLES, CGTG, CGES.

c) Produkty typu CKLPG, CKLPR, CGPG, CGPR mogą nie spełniać w pełni tego wymagania.

d) Płyny słabo rozpuszczalne w wodzie powinny być przygotowane przy użyciu przystosowanych frakcji zgodnie z ASTM D 6081. 
Artykuł powstał na podstawie pracy statutowej pt. Opracowanie technologii smaru przekładniowego dla kolejnictwa - praca INiG - PIB na zlecenie MNiSW; nr zlecenia: 0034/TO/2020, nr archiwalny: DK-4100/0022/2020.

\section{Akty prawne i dokumenty normatywne}

ASTM D 1478-20 Standard Test Method for Low-Temperature Torque of Ball Bearing Grease.

ASTM D 2596-20 Standard Test method for measurement of extreme-pressure properties of lubricating grease (Four-ball method)

ASTM D 6081-19 Standard Practice for Aquatic Toxicity Testing of Lubricants: Sample Preparation and Results Interpretation.

ASTM D 6866:2018 Standard Test Method for Determining the Bio-based Content of Solid, Liquid and Gaseous Samples using Radiocarbon Analysis.

DIN 51350-4:2015 Testing of lubricants - Testing in the four-ball tester - Part 4: Determination of welding load of consistent lubricants.

DIN 51562-1:1999 Viscometry - Measurement of kinematic viscosity by means of the Ubbelohde viscometer - Part 1: Viscometer specification and measurement procedure.

DIN 51802:2017 Testing of lubricants - Testing of the rust-prevention properties of greases - SKF-Emcor-method.

DIN 51805:1974 Testing of lubricants; determination of flow pressure of lubricating greases, Kesternich method.

DIN 51805:2016 Testing of lubricants - Determination of flow pressure of lubricating greases according to Kesternich method - Part 2: Automatic method.

DIN 51807-1:2014 Testing of lubricants - Test of the behaviour of lubricating greases in the presence of water - Part 1: Static test.

DIN 51807-1:2020 Testing of lubricants - Test of the behaviour of lubricating greases in the presence of water - Part 1: Static test.

DIN 51811:2017 Testing of lubricants - Testing of corrosiveness to copper of greases - Copper strip tarnish test.

DIN 51813:2016 Testing of lubricants - Determination of the content of foreign solid matters in lubricating greases - Particle sizes above $25 \mu \mathrm{m}$.

DIN 51819-2:2016 Testing of lubricants - Mechanical-dynamic testing in the roller bearing test apparatus FE8 - Part 2: Test method for lubricating greases - applied test bearing: oblique ball bearing or tapered roller bearing.

DIN 51820-1:1989 Testing of lubricants; analysis of greases by infrared spectrometry; taking and evaluating an infrared spectrum.

DIN 51821-2:2016 Testing of lubricants - Test using the FAG roller bearing grease testing apparatus FE9 - Part 2: Test method.

DIN 51826:2015 Lubricants - Lubricating greases G - Classification and requirements.

DIN 51828-1:2000 Testing of lubricants and related products Determination of the rapid biodegradability - Part 1: General.

DIN 51828-2:1999 Testing of lubricants and related products Determination of the rapid biodegradability - Part 2: Infrared spectrometric method.

DIN ISO 14635-3:2011 Gears - FZG test procedures - Part 3: FZG test method $\mathrm{A} / 2.8 / 50$ for relative scuffing load-carrying capacity and wear characteristics of semifluid gear greases (ISO 14635-3:2005).

DIN ISO 2176:1997 Petroleum products - Lubricating grease Determination of dropping point (ISO 2176:1995).

IP 186:2015 Determination of low temperature torque of lubricating grease.

IP 239:2015 Determination of extreme pressure and anti-wear properties of lubricating fluid and greases - four ball method (European conditions).
IP 396:2017 Determination of dropping point of lubricating grease - Automatic apparatus method.

ISO 1817:2015 Rubber, vulcanized or thermoplastic - Determination of the effect of liquids.

ISO 2137:2007 Petroleum products and lubricants - Determination of cone penetration of lubricating greases and petrolatum.

ISO 2160:1998 Petroleum products - Corrosiveness to copper Copper strip test.

ISO 2176:1995 Petroleum products - Lubricating grease Determination of dropping point

ISO 3104:2020 Petroleum products - Transparent and opaque liquids - Determination of kinematic viscosity and calculation of dynamic viscosity.

ISO 3733:1999 Petroleum products and bituminous materials Determination of water - Distillation method.

ISO 6299:1998 Petroleum products - Determination of dropping point of lubricating greases (wide temperature range).

ISO 6341:2012 Water quality - Determination of the inhibition of the mobility of Daphnia magna Straus (Cladocera, Crustacea) Acute toxicity test.

ISO 7346-1:1996 Water quality - Determination of the acute lethal toxicity of substances to a freshwater fish [Brachydanio rerio Hamilton-Buchanan (Teleostei, Cyprinidae)] - Part 1: Static method.

ISO 8692:2012 Water quality - Fresh water algal growth inhibition test with unicellular green alga.

ISO 9408:1999 Water quality - Evaluation of ultimate aerobic biodegradability of organic compounds in aqueous medium by determination of the oxygen demand in a closed respirometer.

ISO 9439:1999 Water quality - Evaluation of ultimate aerobic biodegradability of organic compounds in aqueous medium - Carbon dioxide evolution test.

ISO 10253:2008 Water quality - Marine algal growth inhibition test with Skeletonema costatum and Phaeodactylum tricornutum.

ISO 11007:1997 Petroleum products and lubricants - Determination of rust-prevention characteristics of lubricating greases.

ISO 11009:2000 Petroleum products and lubricants - Determination of water washout characteristics of lubricating greases.

ISO 12925-1:2018 Lubricants, industrial oils and related products (class L) - Family C (gears) - Part 1: Specifications for lubricants for enclosed gear systems.

ISO/CD 12925-2:2019 Lubricants, Industrial oils and related products (Class L) - Family C (gears) - Part 2: Specifications of categories $\mathrm{CKH}, \mathrm{CKJ}$ and CKM (lubricants open and semi-enclosed gear systems).

ISO/CD 12925-3:2020 Lubricants, Industrial oils and related products (Class L) - Family C (gears) - Part 3 - Specifications for greases for enclosed and open gear systems.

ISO 13737:2004 Petroleum products and lubricants - Determination of low-temperature cone penetration of lubricating greases.

ISO 14593:1999 Water quality - Evaluation of ultimate aerobic biodegradability of organic compounds in aqueous medium Method by analysis of inorganic carbon in sealed vessels ( $\mathrm{CO} 2$ headspace test).

ISO 14635-1:2000 Gears - FZG test procedures - Part 1: FZG test method A/8,3/90 for relative scuffing load-carrying capacity of oils.

ISO 14635-3:2005 Gears - FZG test procedures - Part 3: FZG test method $\mathrm{A} / 2,8 / 50$ for relative scuffing load-carrying capacity and wear characteristics of semifluid gear greases.

ISO 14669:1999 Water quality - Determination of acute lethal toxicity to marine copepods (Copepoda, Crustacea).

ISO 16221:2001 Water quality - Guidance for determination of biodegradability in the marine environment. 
ISO 22285:2018 Petroleum products and lubricants - Determination of oil separation from grease - Pressure filtration method.

ISO 22286:2018 Petroleum products and lubricants - Determination of the dropping point of grease with an automatic apparatus.

NF T60-627:2019 Mineralölerzeugnisse und Schmiermittel Bestimmung des Tropfpunktes von Fett mit einem automatischen Gerät.

OECD 208:2006 Terrestrial Plant Test - Seedling Emergence and Seedling Growth Test.

PN-C-96015:2014 Środki smarowe - Smary plastyczne klasy G Klasyfikacja i wymagania.

PN-ISO 12924:2012 Środki smarowe, oleje przemysłowe i produkty podobne (klasa L) - Grupa X (Smary) - Wymagania.

PN-ISO 6743-6:2020 Środki smarowe, oleje przemysłowe i produkty podobne (klasa L) - Klasyfikacja - Część 6: Grupa C (Przekładnie).
PN-ISO 6743-9:2009 Środki smarowe, oleje przemysłowe i produkty podobne (klasa L) - Klasyfikacja - Część 9: Grupa X (Smary plastyczne).

PN-ISO 6743-99:2009 Środki smarowe, oleje przemysłowe i produkty podobne (klasa L) - Klasyfikacja - Część 99: Postanowienia ogólne.

PN-ISO 8681:2017 Przetwory naftowe i środki smarowe - Metoda klasyfikacji - Definicja klas.

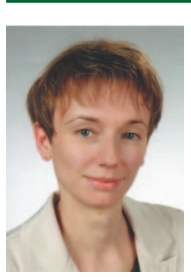

Mgr inż. Agnieszka SKIBIŃSKA

Asystent w Zakładzie Olejów, Środków Smarowych i Asfaltów

Instytut Nafty i Gazu - Państwowy Instytut Badawczy ul. Lubicz 25 A

31-503 Kraków

E-mail: agnieszka.skibinska@inig.pl

OFERTA BADAWCZA ZAKŁADU OLEJÓW, ŚRODKÓW SMAROWYCH I ASFALTÓW

opracowywanie i modyfikacja technologii wytwarzania:

" olejów podstawowych (bazowych), plastyfikatorów naftowych,

" środków smarowych: olejów przemystowych i smarów plastycznych,

» wosków naftowych, (parafin i mikrowosków), wosków i kompozycji specjalnych oraz emulsji woskowych,

» dodatków stosowanych podczas wydobycia i transportu ropy naftowej i gazu ziemnego: inhibitorów korozji, inhibitorów parafin, inhibitorów hydratów, inhibitorów hydratów i korozii, deemulgatorów oraz inhibitorów oporów przeptywu ropy naftowej,

» asfaltów drogowych i przemystowych,

» olejów technologicznych do obróbki metali: emulgujących i nieemulgujących,

» niskokrzepnących płynów do chtodnic samochodowych i spryskiwaczy samochodowych;

- specjalistyczne badania oraz ocena właściwości fizykochemicznych i użytkowych:

" środków smarowych, smarów plastycznych i olejów przemystowych, silnikowych,

» wosków naftowych, wosków specjalnych oraz kompozycji i emulsji woskowych,

» asfaltów drogowych przemystowych oraz emulsji asfaltowych, roztworów i mas asfaltowych oraz innych specyfików asfaltowych;

- opracowywanie zagadnień związanych z gospodarką olejami odpadowymi i odpadami rafineryjnymi;

- sporządzanie ekobilansów procesów technologicznych metodą Oceny Cyklu Życia.

Kierownik: dr inż. Stefan Ptak Adres: ul. Łukasiewicza 1, 31-429 Kraków Telefon: 126177574 Faks: 126177522 E- mail: stefan.ptak@inig.pl

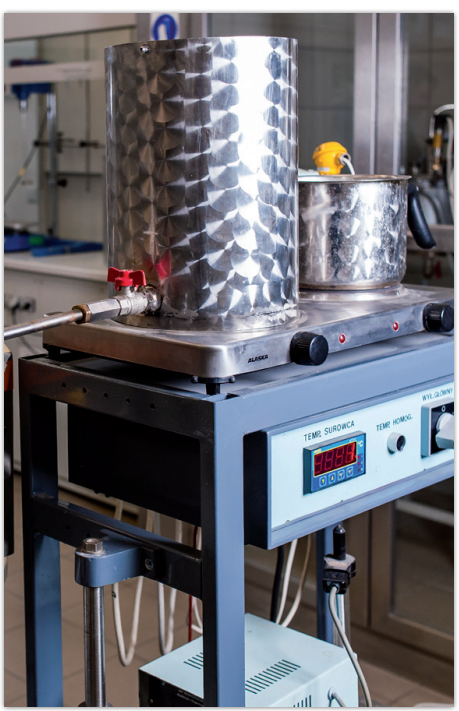

INSTYTUT NAFTY I GAZU

-Państwowy Instytut Badawczy 